\title{
Towards meaningful mobility: a research agenda for movement within and between places in later life
}

\author{
Louise Meijering* (D) \\ Population Research Center (PRC), Urban and Regional Studies Institute (URSI), Faculty of Spatial \\ Sciences, University of Groningen, Groningen, The Netherlands \\ ${ }^{\star}$ Corresponding author. Email: 1.b.meijering@rug.nl
}

(Accepted 4 September 2019; first published online 14 October 2019)

\begin{abstract}
Mobility or physical movement contributes to health and wellbeing in later life. Most studies have focused on the contribution of outdoor mobility to active ageing, but physical and cognitive impairments restrict the mobility of many older adults. This article aims to explore the gaps in the current literature on mobility in later life, and identify required innovations in the field through laying out key areas for future research. It discusses two, largely separate, areas of research, namely on mobility patterns and mobility experiences. The first focuses on quantitative and spatial research on outdoor mobility patterns in terms of routes, timing and transport modes. The second mainly concerns qualitative research on how older adults perceive mobility in their everyday lives. This article identifies three areas for future research on mobility in later life: (a) beyond outdoor movement; (b) diversity in mobility; and (c) the role of time in mobility. To conclude, addressing these areas jointly will contribute to further unpacking the concept of mobility as meaningful practice and to integrating quantitative and qualitative methods when studying mobility in later life. This will result in policy inputs on the mobility and wellbeing of our ageing population.
\end{abstract}

Keywords: mobility; mobility patterns; mobility experiences; later life; diversity; research agenda

\section{Introduction}

Mobility in later life is very important, as it can lead to a sense of independence, self-directedness and social engagement (Mollenkopf et al., 2011; Isherwood et al., 2017; Franke et al., 2018; Graham et al., 2020). Research has shown that mobility has both an extrinsic and an intrinsic value. In other words, mobility both enables older adults to go to places and to enjoy moving around just for the sake of it (Graham et al., 2020). In other words, mobility as an embodied practice links the home environment with other places, but should also be seen as a key aspect of freedom and autonomy (Schwanen and Ziegler, 2011; Schwanen et al., 
2012). Hence, the experienced importance of being mobile stays high in later life (Mollenkopf et al., 2011; Hjorthol, 2013). The aim of this Forum Article is to set out a research agenda that explores the gaps in the current literature on mobility in later life and identifies required innovations in the field through laying out key areas for future research.

In this research agenda, mobility is defined as physical movement within and between places. This includes physical movement between points $\mathrm{A}$ and $\mathrm{B}-$ or mobility patterns - as well as mobility experiences, which embrace the purpose of movement, such as engaging in social interactions, work and leisure activities (Sheller and Urry, 2006; Cresswell, 2010). Small-scale movements on foot, such as getting up from a chair and walking from the living room to the kitchen to make a cup of coffee, are also mobility (Weening-Dijksterhuis et al., 2011). Not included in this article are non-physical forms of mobility, such as digital and psychological mobility (Ziegler and Schwanen, 2011).

Many older adults experience physical and cognitive impairments that impact on their physical movement or mobility. Yet, gerontological discourse on active and successful ageing emphasises that older adults need to invest in being active and healthy rather than in dealing with physical and cognitive impairments that are part of the ageing process. This focus on being active and healthy frames older adults who are less healthy implicitly as unsuccessful (Foster and Walker, 2014; Martinson and Berridge, 2015; Rubinstein and de Medeiros, 2015; Lodge et al., 2016). The active ageing discourse tends to ignore the reality that many older adults are restricted in their mobility, both indoors and outdoors. In the context of these restrictions, older adults have to make choices, for instance vacuum cleaning the house may imply no energy to walk to the supermarket. These often and unduly overlooked choices make mobility meaningful.

Mobility in later life is also affected by government policies, especially in the context of ageing populations. To manage costs, governments are tending to cut back on social and health-care services. This may result in reduced social participation and increased social exclusion of disadvantaged groups, including older adults (see Andrews et al., 2012; Lucas, 2012; Stjernborg, 2017; Battista and Manaugh, 2018). Further research on the gaps identified in this research agenda will provide input to policy makers on the opportunities for and constraints to the mobility of different categories of older adults, that is grounded in their everyday lived experiences. In the long term, the generated knowledge will contribute to improving the physical mobility and wellbeing of our ageing populations.

\section{State of the art and scientific challenges}

This section gives an overview of the current state of research on mobility in later life and connected scientific challenges. A review of the literature on mobility in later life has led me to divide the section into two parts: (a) mobility patterns, concerning actual, often quantified mobility and (b) mobility experiences, concerning perceived, often qualitatively studied, mobility. This division between patterns and experiences aligns with the more general methodological 'divide' between quantitative and qualitative research that has recently been identified in health geography (Rosenberg, 2016). 


\section{Mobility patterns in later life}

Traditionally, mobility has been conceptualised as movement from one location to the other, typically through outdoor movement. This has resulted in a large body of work on mobility patterns, also on older adults, which finds its roots in Hägerstrand's time-geography. Time-geography looks at people's spatial environments and movement as situated in time, using space-time paths. Hägerstrand studied how constraints (and enablers) impact whether and how a person can be at a particular place at a particular time (see Gregory et al., 2009). Numerous studies have shown how outdoor mobility or movement between places can contribute to active and healthy ageing (for instance, see Shoval et al., 2010; Winters et al., 2015; Hirsch et al., 2016; Voss et al., 2016). Typically, such studies measure objective outdoor mobility patterns in terms of routes, timing and transport modes. These studies have used quantitative methods, such as surveys, travel diaries, accelerometers and, with recent technology developments, GPS tracking, to characterise movement in terms of speed, length, timing and frequency of the movement. These studies have demonstrated that mobility achievements in terms of the frequency and range of outdoor movement patterns tend to decrease with age (Shoval et al. 2010, 2011; Rantanen et al., 2012; Umstattd Meyer et al., 2013). A specific area of research focuses on the effect of driving cessation on outdoor mobility patterns in later life. Overall, driving cessation does lead to a reduction in outdoor mobility and quality of life (Musselwhite and Haddad, 2010). It seems that after retirement, older adults make less use of their cars (Siren and Haustein, 2015). Several studies have shown that older adults require more help with moving around upon driving cessation (Siren and Haustein, 2015; Isherwood et al., 2017). With regard to the effect of driving cessation on the use of other forms of transport, such as walking, cycling, driving along as a passenger and public transport, the evidence is mixed: both increased use of these other forms (Siren and Haustein, 2015) as well as no increased use (King and Scott-Parker, 2017) have been reported. Furthermore, planning for driving cessation, as well as gradually reducing car use, may contribute to a higher quality of life after cessation (Musselwhite, 2011; Musselwhite and Shergold, 2013).

Within the research area of mobility patterns, there are several studies that have focused on how the outdoor mobility of older adults can contribute to active ageing, often by linking mobility to active forms of transport, such as walking and cycling. These studies have tended to focus on healthy and active older adults (Winters et al., 2015; Hirsch et al., 2016; Voss et al., 2016). A few studies have been carried out on the mobility patterns of older adults affected by impairments such as dementia (Shoval et al., 2011) and stroke (Evans et al., 2012), and on nursing home residents (Karakaya et al., 2009). One study by Shoval et al. (2011) demonstrated that the achieved outdoor mobility of cognitively impaired older adults is more severely restricted than that of healthy older adults. Furthermore, another study found that functional limitations in mobility, such as difficulties with walking, climbing stairs and carrying weights, are associated with being less active (Litwin and Levinson, 2018). However, it remains largely unclear how mobility patterns in older adults are affected by physical and cognitive impairments that are associated with later life. Therefore, research should be done to increase 
understanding of the mobility patterns of healthy and impaired older adults. Relevant impairments associated with ageing could include diabetes, cardiovascular diseases, memory issues, arthrosis and osteoporosis.

Most research on objectively measured mobility patterns has focused on outdoor mobility. The few studies on indoor movement patterns of older adults have relied mainly on subjective self-reported measurements (Mänty et al., 2012, 2014). This leaves a significant gap in knowledge because older adults spend as much as 80 per cent of their time at home (Baltes et al., 1999; Sixsmith et al., 2014). They spend even more time indoors, or within places, when indoor places beyond the home are included and thus most of their mobility is likely to be indoors. Furthermore, more indoor mobility may explain reduced outdoor mobility, and the reverse may be the case. Hence, indoor movement is a vital link in a comprehensive understanding of mobility patterns in later life. Thus, with the focus on outdoor mobility, many studies have overlooked most physical movement or mobility in later life that takes place indoors. Therefore, it is vital that researchers take up the challenge to include indoor mobility in studies on mobility patterns in later life.

Furthermore, mobility patterns differ between socio-cultural contexts as some are more conducive to physical movement in later life than others (Green et al., 2014). For instance, older adults may have the freedom to go out and manage their everyday lives; or it may not be considered appropriate for either men or women to venture outdoors; or there are limited opportunities for outdoor physical movement, such as in car-dependent societies. However, there are no comparative studies of mobility in later life, apart from one cross-country comparison of mobility patterns within Europe (Gagliardi et al., 2007). Furthermore, most mobility research is carried out in the Western world (Nordbakke and Schwanen, 2014; Kwan and Schwanen, 2016). Research is needed that studies and compares the mobility patterns of older adults in diverse socio-cultural contexts in and beyond the Western world.

Summarising the above, the following questions could guide a research agenda with regard to mobility patterns in later life: what do the indoor and outdoor mobility patterns of older adults look like in terms of speed, length, timing and frequency of movement, number and types of places frequented, mode of transport and travel companions? More specifically: how much do older adults move indoors and outdoors, respectively? To what extent do these mobility patterns differ between healthy and impaired older adults? How do the movement patterns of older adults differ between socio-cultural settings?

Methods that could be used to address these questions include GPS tracking, smart insole tracking, activity watch tracking and activity diaries. Measuring indoor movements is technologically challenging, in particular. Accelerometers and/or activity watches used to measure indoor mobility (in terms of physical activity) have problems with accuracy and wear-ability (Voss et al., 2016). Some advances have been made in measuring indoor mobility using Wi-Fi technology in controlled settings, such as on a university campus (Petrenko et al., 2014; Torres-Sospedra et al., 2015). However, such measurement is still difficult in the real world with less Wi-Fi coverage, especially in indoor spaces beyond the home. 


\section{Mobility experiences of older adults}

Besides research on mobility patterns, there is an area of research on subjective mobility experiences, which centres on how older adults perceive their mobility in their everyday lives. This area of research has developed after the so-called mobility turn (see Sheller and Urry, 2006), in response to some of the shortcomings of research on mobility patterns that are grounded in its positivist foundations. Research on mobility experiences is often qualitative and focuses on how older adults choose to exert their physical mobility to engage in specific activities and go to particular places, how they experience movement, how they feel about their physical mobility, and whether there are places that they would like to go but that they cannot reach. These studies have shown that the mobility of older adults is closely related to that of their significant others, and often focuses on engaging in social and leisure activities (Burnett and Lucas, 2010; Garder, 2014; Aird and Buys, 2015; Goins et al., 2015). Studies on mobility experiences have also shown that mobility can contribute to wellbeing by providing a sense of autonomy, selfreliance, choice and social usefulness (Mollenkopf et al., 2011; Ziegler and Schwanen, 2011; Zeitler and Buys, 2015).

Similar to research on mobility patterns, these studies on subjective mobility experiences have mainly been done on relatively active and healthy older adults (Andrews et al., 2012). Some studies using traditional qualitative methods, such as in-depth interviews, have addressed the mobility of impaired older adults, including nursing home residents (Karakaya et al., 2009; Klaassens and Meijering, 2015) and stroke survivors (Nanninga et al., 2018). To the best of my knowledge, no comparative studies have been done on the mobility experiences of older adults with different impairments. Therefore, comparative research that foregrounds the mobility experiences of healthy and impaired older adults is required to articulate the frailties and strengths of older adults. This will include why and where they move, the choices they make and the barriers they experience. Articulating the frailties and strengths of older adults can in part be achieved through tying in with the existing literature on experiences of (powered) assistive devices, such as walkers, mobility scooters and (powered) wheelchairs. Research in this area has shown that using a device is an opportunity that can enhance and facilitate movement, but that it can also enhance stigma and invisibility (Korotchenko and Clarke, 2016; Labbé et al., 2020). Furthermore, some older adults may not experience being mobile. Rather, their experiences are of inactivity or stillness (Cresswell, 2012; Hitchings et al., 2018). Thus, to gain better understanding of mobility experiences in later life, further studies on how experiences of stillness and movement alternate could be insightful.

Furthermore, and also similar to the research on mobility patterns, few studies have been done on how older adults experience their movement within places, such as the home. This is a major gap in our understanding of the mobility of older adults especially because they spend increasing amounts of time indoors (Gibson et al., 2012; Rowles and Bernard, 2013; Sixsmith et al., 2014; Wiles et al., 2012, 2017). Insights into experiences of indoor movement will generate pivotal insights into what mobility experiences in later life can be. These insights will counter predominant negative conceptions of the home and indoor places in later life. The home in 
later life is often conceptualised as a place to which people are bound, and which is associated with inactivity and loneliness. Older adults would have to leave the home in order to break out of this (Iwarsson et al., 2007; Ziegler and Schwanen, 2011), an assumption that could be challenged when movement within places is studied in further detail. Furthermore, older women have been found to engage more in indoor and home activities (Rioux, 2005; Gagliardi et al., 2007; Douma et al., 2017), whereas men tend to emphasise independence most (Isherwood et al., 2017). Further insight into the gender dimension of mobility experience could be obtained by studying how engaging in home-based activities colours experiences of mobility. This does align with the more general call for looking into the gendered aspects of daily mobility (Law, 1999; Uteng and Cresswell, 2008). Finally, and again similar to research on mobility patterns, studies on mobility experiences beyond the Western world as well as comparative studies have been sparse (for an exception, see Uteng and Lucas, 2017). Therefore, research into older adults in the global South, as well as cross-cultural comparisons, could strengthen and deepen the understanding of mobility experiences.

Based on the above, the following questions could guide a research agenda on mobility experiences in later life: How are mobility experiences in later life impacted by health? How do older adults experience their indoor movement, in relation to outdoor movement as well as stillness? What is the role of socio-economic status and gender in mobility experiences? What are the differences and similarities in mobility experiences between older adults in different socio-cultural contexts?

Methods that could be used to address these questions include qualitative mobile interviews, in-depth interviews, participant observation, activity diaries as well as quantitative assessment of mobility by short surveys. Such surveys could be administered on paper, or they could be web-based, for instance through a smartphone app. These methods require different skills from older adults and not all methods can be used with all older adults. For example, although this is changing with the ageing of the population, not all older adults can operate a smartphone. Older people with memory issues or other cognitive impairments may have difficulties in expressing themselves orally or in writing.

\section{Areas for future research}

In the previous section, I have discussed what we know about mobility patterns and experiences in later life as well as the current gaps in research. It is important to note that these two areas have mainly studied mobility separately and disconnectedly, with the risk of overlooking other key components of mobility in later life. Therefore, it is important to connect mobility patterns and experiences by looking at the identified research gaps and questions in a more overarching way. This will open up new ways of thinking about mobility in later life, underscoring what older adults can do (Adey et al., 2014; Adey, 2017). Based on the research gaps and questions identified in the previous sections, I propose three more general areas for future research on mobility in later life: (a) mobility beyond outdoor movement; (b) diversity in mobility; and (c) the role of time in mobility. The first two areas for research come forward quite directly from mirroring gaps in both research on mobility patterns and mobility experiences. They include indoor movement, 
as well as the role of health and impairment and socio-cultural context. The third area, the role of time, did come up in the previous sections more implicitly and will be made more explicit here.

\section{Mobility beyond outdoor movement}

Based on the review of research on mobility patterns and experiences above, it becomes clear that there is a major gap in studying indoor movement as part of mobility, in general, and in connecting in- and outdoor movement, in particular. Connecting patterns of indoor movement, in terms of speed, length, timing and frequency, with their experiences will help to obtain a more comprehensive picture of mobility in later life. Studying indoor mobility will also help to foreground the importance of inactivity or stillness, as well as the alternations between movement and stillness. Foregrounding indoor movement in mobility research in later life will enrich current debates on active and healthy ageing, as it will help to foreground that being indoors does not necessarily equal being inactive and unhealthy (see Hitchings et al., 2018). Also, looking at both movement within and between places will help to uncover the enabling and disabling aspects of the physical and social environment for mobility, a recommendation that has been made in earlier research as well (Mollenkopf et al., 2011; Lloyd and Stirling, 2015; Franke et al., 2018; Litwin and Levinson, 2018; Graham et al., 2020; Labbé et al., 2020). For instance, what is the role of the neighbourhood and broader community in mobility in later life? To what extent can a social network mitigate the negative effects of mobility impairments? What aspects of the physical and social environment act as barriers and enablers to mobility, both with and without use of assistive devices?

\section{Diversity in mobility}

What we can conclude from the previous sections is that mobility in later life is mainly studied among relatively healthy older adults in the Western world, which means that diversity in mobility requires further research. I would argue that it is important to look at diversity beyond health status and socio-cultural context, to also include, for instance, diversity in socio-economic status, gender and ethnicity (see also Franke et al., 2018; Hitchings et al., 2018). There is some research on the outdoor mobility patterns and experiences of older adults with a low income, e.g. by Adorno et al. (2018) and Franke et al. (2017, 2018), but drawing out the differences and similarities in mobility of older adults from different socioeconomic backgrounds would enrich insights into movement in later life.

I identified two promising approaches that will help achieve this, one theoretical and one methodological. A potentially relevant theoretical approach to study diversity in mobility is Sen's (1999) capability approach. The capability approach foregrounds the (different) opportunities that older adults have, as well as potential sources of vulnerability and inequality, and the fact that they can choose which opportunities to put into practice. In the end, the capability approach emphasises achievements, or beings and doings, as outcomes. In the context of this research agenda, these outcomes can be labelled mobility practices. Therefore, using the capability approach enables a shift in focus towards the mobility practices that are 
meaningful for different (groups of) older adults. These include the role of sociocultural context and socio-economic status, gender, ethnicity, and physical and cognitive impairments.

A promising methodological approach is grounded visualisation (Knigge and Cope, 2006). Grounded visualisation was developed to integrate diverse forms of data to uncover the multiple meanings associated with a topic and to contribute to theory building. With foundations in grounded theory and visualisation, this is a rigorous, recursive and reflexive approach to analyse qualitative, spatial and quantitative data, and is attuned to multiple meanings (Franke et al., 2017). Grounded visualisation contributes to theory building that is grounded in everyday life, and in broader patterns and socio-cultural contexts. Through grounded visualisation, comparison and integration of mobility patterns and experiences could be achieved. This would help to identify similarities and differences in terms of places frequented, routes taken, activities undertaken and social interactions (see also Kwan and Ding, 2008).

\section{The role of time in mobility}

In the introduction to research on mobility patterns, the connection between mobility research and Hägerstrand's time-geography was mentioned. Implicitly, the role of time has been addressed above, but I want to draw it out as an important area for further research more explicitly here. There is some evidence that outdoor mobility in later life varies over time. Older adults tend to avoid going out at night and engage less in outdoor mobility in adverse weather circumstances (Phillips et al., 2013; Portegijs et al., 2014; Lager et al., 2016; Meijering and Weitkamp, 2016; Finlay, 2018). As most studies have tended to focus on mobility in later life at one timepoint, little is known about how indoor and outdoor mobility patterns vary over time, measured on different timescales: time of day, week, month and year. These variations over time should be connected to other circumstances, such as how an older adults feels, the availability of other people and/or services, and weather circumstances. This would facilitate a more longitudinal approach to mobility in later life. When applying a longitudinal approach, a lifecourse perspective may be useful to get insight into the dynamic nature of mobility at a larger timescale (Labbé et al., 2020).

The concept of mobility is well suited to studying the temporality of movement (Adey et al., 2014), but it is difficult to put in practice in the collection of empirical data. I would like to emphasise some promising avenues in this regard. First, Ecological Momentary Assessment (Kwan, 2012) is a useful strategy for measuring subjective experiences of mobility in real time. Real-time measurements can be achieved, for instance, through using a smartphone app or through calling participants at different (randomised) times of the day. Second, mobile interviews, conducted while on the move, can provide insight into experiences of routes and associated obstacles are discussed as they are encountered (see Bell et al., 2015; Lager et al., 2016). Third, collecting data in different seasons will generate insight into the effect of seasonal weather variations on mobility practices. Thus, foregrounding the role of time in mobility will enable us to understand how and 
why patterns and experiences of movement in later life differ, depending on time of day, week and year.

\section{Conclusion}

Addressing the research areas identified in this research agenda will deliver pioneering outcomes on mobility in later life on three interrelated levels. Theoretically, it will contribute to further unpacking the concept of mobility as a meaningful practice. It will provide major new transferable insights into indoor and outdoor mobility in later life that have the potential to change prevailing approaches to mobility research in different socio-cultural and socio-economic contexts. Methodologically, it will open up innovative mixed-method, cross-cultural and cross-category approaches to topics that are often studied by means of specific case studies. Substantively, the research agenda will provide theory-driven insights that guide policies for healthy ageing. Addressing diversity in mobility in later life will provide input for concrete, culturally sensitive interventions that address how older adults can maintain levels of mobility that they perceive as adequate. Research on combined in- and outdoor mobility in later life will provide policy makers with a sounder basis for policy development and decision-making. Specifically, the research agenda will provide input on how the mobility-related policies for agefriendly cities can be improved (World Health Organization, 2007, 2015), as well as for new technologies that can facilitate mobility in later life. Finally, and perhaps most importantly, it will contribute to giving voice to the views, needs and claims of older adults with impairments that have typically been kept out of the dominant policy discourses of active, successful and healthy ageing.

Acknowledgements. An earlier version of this paper was presented at the International Conference on New Directions for Research on Aging: Work, Care and Mobility, held at Manipal Academy of Higher Education (MAHE), India, on 1 and 2 March 2019. I would like to thank the organisers, Ajay Bailey and Martin Hyde, as well as the participants, for their useful comments on the paper. Also, I would like to thank two anonymous reviewers for their constructive feedback that helped improve the article.

Financial support. The Meaningful Mobility project has received funding from the European Research Council (ERC) under the European Union's Horizon 2020 research and innovation programme (grant agreement number 802202).

Ethical standards. No ethics approval was required.

\section{References}

Adey P (2017) Mobility. Oxford: Taylor \& Francis.

Adey P, Bissell D, Hannam K, Merriman P and Sheller M (2014) The Routledge Handbook of Mobilities. London: Routledge.

Adorno G, Fields N, Cronley C, Parekh R and Magruder K (2018) Ageing in a low-density urban city: transportation mobility as a social equity issue. Ageing \& Society 38, 296-320.

Aird RL and Buys L (2015) Active aging: exploration into self-rating of 'being active' out-of-home physical activity, and participation among older Australian adults living in four different settings. Journal of Aging Research 2015, 501823, 1-3.

Andrews GJ, Hall E, Evans B and Colls R (2012) Moving beyond walkability: on the potential of health geography. Social Science \& Medicine 75, 1925-1932. 
Baltes MM, Maas I, Wilms H, Borchelt M and Little TD (1999) Everyday competence in old and very old age: theoretical considerations and empirical findings. In Baltes PB and Mayer KU (eds), The Berlin Aging Study: Aging from 70 to 100. Cambridge: Cambridge University Press, pp. 384-402.

Battista GA and Manaugh K (2018) Stores and mores: towards socializing walkability. Journal of Transport Geography 67, 53-60.

Bell SL, Phoenix C, Lovell R and Wheeler BW (2015) Using GPS and geo-narratives: a methodological approach for understanding and situating everyday green space encounters. Area 47, 88-96.

Burnett P and Lucas S (2010) Talking, walking, riding and driving: the mobilities of older adults. Journal of Transport Geography 18, 596-602.

Cresswell T (2010) Towards a politics of mobility. Environment and Planning D 28, 17-31.

Cresswell T (2012) Mobilities II: still. Progress in Human Geography 36, 645-653.

Douma L, Steverink N, Hutter I and Meijering L (2017) Exploring subjective well-being in older age by using participant-generated word clouds. The Gerontologist 57, 229-239.

Evans CC, Hanke TA, Zielke D, Keller S and Ruroede K (2012) Monitoring community mobility with global positioning system technology after a stroke: a case study. Journal of Neurologic Physical Therapy 36, 68-78.

Finlay JM (2018) 'Walk like a penguin': older Minnesotans' experiences of (non)therapeutic white space. Social Science \& Medicine 198, 77-84.

Foster L and Walker A (2014) Active and successful aging: a European policy perspective. The Gerontologist 55, 83-90.

Franke T, Sims-Gould J, Chaudhury H, Winters M and McKay H (2018) 'It makes your life worthwhile. It gives you a purpose in living': mobility experiences among active older adults with low income. Ageing \& Society 39, 1639-1666.

Franke T, Winters M, McKay H, Chaudhury H and Sims-Gould J (2017) A grounded visualization approach to explore sociospatial and temporal complexities of older adults' mobility. Social Science \& Medicine 193, 49-69.

Gagliardi C, Spazzafumo L, Marcellini F, Mollenkopf H, Ruoppila I, Tacken M and Szémann Z (2007) The outdoor mobility and leisure activities of older people in five European countries. Ageing \& Society 27, 683-700.

Garder P (2014) The role of social engagement and identity in community mobility among older adults ageing in place. Disability and Rehabilitation 36, 1249-1257.

Gibson BE, Secker B, Rolfe D, Wagner F, Parke B and Mistry B (2012) Disability and dignity-enabling home environments. Social Science \& Medicine 74, 211-219.

Goins RT, Jones J, Schure M, Rosenberg DE, Phelan EA, Dodson S and Jones DL (2015) Older adults' perceptions of mobility: a metasynthesis of qualitative studies. The Gerontologist 55, 929-942.

Graham H, De Bell S, Flemming K, Sowden A, White P and Wright K (2020) Older people's experiences of everyday travel in the urban environment: a thematic synthesis of qualitative studies in the United Kingdom. Ageing \& Society 40, 842-868.

Green J, Jones A and Roberts H (2014) More than A to B: the role of free bus travel for the mobility and wellbeing of older citizens in London. Ageing \& Society 34, 472-494.

Gregory D, Johnston R, Pratt G, Watts MJ and Whatmore S (2009) The Dictionary of Human Geography, 5th Edn. Oxford: Blackwell.

Hirsch JA, Winters M, Ashe MC, Clarke PJ and McKay HA (2016) Destinations that older adults experience within their GPS activity spaces: relation to objectively measured physical activity. Environment and Behavior 48, 55-77.

Hitchings R, Venn S and Day R (2018) Assumptions about later-life travel and their implications: pushing people around? Ageing \& Society 38, 1-18.

Hjorthol R (2013) Transport resources, mobility and unmet transport needs in old age. Ageing \& Society 33, 1190-1211.

Isherwood L, King D and Luszcz M (2017) Widowhood in the fourth age: support exchange, relationships and social participation. Ageing \& Society 37, 188-212.

Iwarsson S, Wahl H, Nygren C, Oswald F, Sixsmith A, Sixsmith J and Tomsone S (2007) Importance of the home environment for healthy aging: conceptual and methodological background of the European ENABLE-AGE project. The Gerontologist 47, 78-84. 
Karakaya MG, Bilgin SÇ, Ekici G, Köse N and Otman AS (2009) Functional mobility, depressive symptoms, level of independence, and quality of life of the elderly living at home and in the nursing home. Journal of the American Medical Directors Association 10, 662-666.

King MJ and Scott-Parker BJ (2017) Older male and female drivers in car-dependent settings: how much do they use other modes, and do they compensate for reduced driving to maintain mobility. Ageing \& Society 37, 1249-1267.

Klaassens M and Meijering L (2015) Experiences of home and institution in a secured nursing home ward in the Netherlands: a participatory intervention study. Journal of Aging Studies 34, 92-102.

Knigge L and Cope $\mathbf{M}$ (2006) Grounded visualization: integrating the analysis of qualitative and quantitative data through grounded theory and visualization. Environment and Planning A 38, 2021-2037.

Korotchenko A and Clarke L (2016) Canadian power mobility device users' experiences of ageing with mobility impairments. Ageing \& Society 36, 1238-1253.

Kwan M (2012) The uncertain geographic context problem. Annals of the Association of American Geographers 102, 958-968.

Kwan M and Ding G (2008) Geo-narrative: extending geographic information systems for narrative analysis in qualitative and mixed-method research. Professional Geographer 60, 443-465.

Kwan M and Schwanen T (2016) Geographies of mobility. Annals of the American Association of Geographers 106, 243-256.

Labbé D, Mortenson W, Rushton P, Demers L and Miller W (2020) Mobility and participation among ageing powered wheelchair users: using a lifecourse approach. Ageing \& Society 40, 626-642.

Lager D, Huigen PPP and van Hoven B (2016) Rhythms, ageing and neighbourhoods. Environment and Planning A 48, 1565-1580.

Law R (1999) Beyond 'women and transport': towards new geographies of gender and daily mobility. Progress in Human Geography 23, 567-588.

Litwin $\mathbf{H}$ and Levinson M (2018) The association of mobility limitation and social networks in relation to late-life activity. Ageing \& Society 38, 1771-1790.

Lloyd BT and Stirling T (2015) The will to mobility: life-space satisfaction and distress in people with dementia who live alone. Ageing \& Society 35, 1801-1820.

Lodge C, Carnell E and Coleman M (2016) The New Age of Ageing: How Society Needs to Change. Bristol, UK: Policy Press.

Lucas K (2012) Transport and social exclusion: where are we now? Transport Policy 20, 105-113.

Mänty M, Ekmann A, Thinggaard M, Christensen K and Avlund K (2012) Fatigability in basic indoor mobility in nonagenarians. Journal of the American Geriatric Society 60, 1279-1285.

Mänty M, Ekmann A, Thinggaard M, Christensen K and Avlund K (2014) Indoor mobility-related fatigue and muscle strength in nonagenarians: a prospective longitudinal study. Aging Clinical and Experimental Research 26, 39-46.

Martinson M and Berridge C (2015) Successful ageing and its discontents: a systematic review of the social gerontology literature. The Gerontologist 55, 58-69.

Meijering $\mathbf{L}$ and Weitkamp $\mathbf{G}$ (2016) Numbers and narratives: developing a mixed methods approach to understand mobility in later life. Social Science \& Medicine 168, 200-206.

Mollenkopf H, Hieber A and Wahl H (2011) Continuity and change in older adults' perceptions of out-of-home mobility over ten years: a qualitative-quantitative approach. Ageing \& Society 31, 782-802.

Musselwhite C (2011) The importance of driving for older people and how the pain of driving cessation can be reduced. Signpost: Journal of Dementia and Mental Health 15, 22-26.

Musselwhite C and Haddad H (2010) Mobility, accessibility and quality of later life. Quality in Ageing and Older Adults 11, 25-37.

Musselwhite CBA and Shergold I (2013) Examining the process of driving cessation in later life. European Journal of Ageing 10, 89-100.

Nanninga CS, Meijering L, Schönherr MC, Postema K and Lettinga AT (2018) Unpacking community mobility: a preliminary study into the embodied experiences of stroke survivors. Disability \& Rehabilitation 40, 2015-2024.

Nordbakke S and Schwanen T (2014) Well-being and mobility: a theoretical framework and literature review focusing on older people. Mobilities 9, 104-129.

Petrenko A, Sizo A, Qian W, Knowles D, Tavassolian A, Stanley K and Bell S (2014) Exploring mobility indoors: an application of sensor-based and GIS systems. Transactions in GIS 18, 351-369. 
Phillips J, Walford N, Hockey A, Foreman N and Lewis M (2013) Older people and outdoor environments: pedestrian anxieties and barriers in the use of familiar and unfamiliar spaces. Geoforum 47, $113-124$.

Portegijs E, Iwarsson S, Rantakokko M, Viljanen A and Rantanen T (2014) Life-space mobility assessment in older people in Finland; measurement properties in winter and spring. BMC Research Notes 7 , 323-331.

Rantanen T, Portegijs E, Viljanen A, Eronen J, Saajanaho M, Tsai LT and Rantakokko M (2012) Individual and environmental factors underlying life space of older people - study protocol and design of a cohort study on life-space mobility in old age (LISPE). BMC Public Health 12, 1018-1034.

Rioux L (2005) The well-being of aging people living in their own homes. Journal of Environmental Psychology 25, 231-243.

Rosenberg M (2016) Health geography II: 'dividing' health geography. Progress in Human Geography 40, 546-554.

Rowles GD and Bernard M (2013) The meaning and significance of place in old age. In Rowles GD and Bernard M (eds), Environmental Gerontology. New York, NY: Springer, pp. 3-24.

Rubinstein RL and de Medeiros K (2015) 'Successful aging', gerontological theory and neoliberalism: a qualitative critique. The Gerontologist 55, 34-42.

Schwanen T, Banister D and Bowling A (2012) Independence and mobility in later life. Geoforum 43, $1313-1322$.

Schwanen T and Ziegler F (2011) Wellbeing, independence and mobility: an introduction. Ageing \& Society 31, 719-733.

Sen A (1999) Development as freedom. Oxford: Oxford University Press.

Sheller M and Urry J (2006) The new mobilities paradigm. Environment and Planning A 38, 207-226.

Shoval N, Auslander G, Cohen-Shalom K, Isaacson M, Landau R and Heinik J (2010) What can we learn about the mobility of the elderly in the GPS era? Journal of Transport Geography 18, 603-612.

Shoval N, Wahl HW, Auslander G, Isaacson M, Oswald F, Edry T and Heinik J (2011) Use of the global positioning system to measure the out-of-home mobility of older adults with differing cognitive functioning. Ageing \& Society 31, 846-869.

Siren A and Haustein S (2015) What are the impacts of giving up the driving licence? Ageing \& Society 35, 1821-1838.

Sixsmith J, Sixsmith A, Malmgren Fänge A, Nauman D, Kucsera C, Tomson S and Woolrych R (2014) Healthy ageing and home: the perspectives of very old people in five European countries. Social Science \& Medicine 106, 1-9.

Stjernborg V (2017) The meaning of social participation for daily mobility in later life: an ethnographic case study of a senior project in a Swedish urban neighbourhood. Ageing International 42, 374-391.

Torres-Sospedra J, Avariento J, Rambla D, Montoliu R, Casteleyn S, Benedito-Bordonau $M$ and Huerta J (2015) Enhancing integrated indoor/outdoor mobility in a smart campus. International Journal of Geographical Information Science 29, 1955-1968.

Umstattd Meyer MR, Janke MC and Beaujean AA (2013) Predictors of older adults' personal and community mobility: using a comprehensive theoretical mobility framework. The Gerontologist 54, 398-408.

Uteng TP and Cresswell T (eds) (2008) Gendered Mobilities. Aldershot, UK: Ashgate.

Uteng TP and Lucas K (eds) (2017) Urban Mobilities in the Global South. London: Routledge.

Voss C, Sims-Gould J, Ashe MC, McKay HA, Pugh C and Winters M (2016) Public transit use and physical activity in community-dwelling older adults: combining GPS and accelerometry to assess transportation-related physical activity. Journal of Transport \& Health 3, 191-199.

Weening-Dijksterhuis E, Greef MHG, Scherder EJA, Slaets JPJ and van der Schans CP (2011) Frail institutionalized older persons: a comprehensive review on physical exercise, physical fitness, activities of daily living, and quality of life. American Journal of Physical Medicine \& Rehabilitation 90, 156-168.

Wiles JL, Leibing A, Guberman N, Reeve J and Allen RES (2012) The meaning of 'ageing in place' to older people. The Gerontologist 52, 357-366.

Wiles JL, Rolleston A, Pillai A, Broad J, The R, Gott M and Kerse N (2017) Attachment to place in advanced age: a study of the LILACS NZ cohort. Social Science \& Medicine 185, 27-37. 
Winters M, Voss C, Ashe MC, Gutteridge K, McKay H and Sims-Gould J (2015) Where do they go and how do they get there? Older adults' travel behaviour in a highly walkable environment. Social Science \& Medicine 133, 304-312.

World Health Organization (2007) Global Age-friendly Cities: A Guide. Geneva: World Health Organization.

World Health Organization (2015) Measuring the Age-friendliness of Cities: A Guide to Using Core Indicators. Geneva: World Health Organization.

Zeitler E and Buys L (2015) Mobility and out-of-home activities of older people living in suburban environments: 'Because I'm a driver, I don't have a problem'. Ageing \& Society 35, 785-808.

Ziegler F and Schwanen T (2011) 'I like to go out to be energised by different people': an exploratory analysis of mobility and well-being in later life. Ageing \& Society 31, 758-781.

Cite this article: Meijering L (2021). Towards meaningful mobility: a research agenda for movement within and between places in later life. Ageing \& Society 41, 711-723. https://doi.org/10.1017/S0144686X19001296 